\title{
ANALISIS KEPUTUSAN KONSUMEN TERHADAP PEMBELIAN JERUK KINTAMANI DI KOTA DENPASAR
}

\author{
Jefri Yosafat, Sri Mulyani*, Amna Hartiati \\ PS Teknologi Industri Pertanian, Fakultas Teknologi Pertanian, Universitas Udayana, Kampus Bukit \\ Jimbaran, Badung, Kode pos : 80361; Telp/Fax : (0361) 701801.
}

Diterima 04 Februari 2019 / Disetujui 16 Februari 2019

\begin{abstract}
The objectives of this research were to analyze the factor which influence of consumer decision to buy Kintamani orange. This research were using a factor analyze by using Microsoft Excel and SPSS 25.0. The data obtained from the questionnaire which spread to the consumer of Kintamani orange. The results show that there are 24 variable divided into 5 factor which influence of consumer decision to buy Kintamani orange. The five factors are characteristic of orange corresponding to the price and competitor, benefit and quality corresponding to the price and product category, the origin of orange corresponding to benefit and consumer perception, the category of orange consumen, and the orange resistance. The factor that the most influence of consumer decision to buy Kintamani orange is taste (The taste of Kintamani orange is a mixture of sweet and sour). The research proposed are to an information to people about Kintamani orange, and an information to the orange farmer and seller of Kintamani orange about the the factor and the main factor that influence consumer to buy Kintamani orange and the special benefit is as a reference knowledge to academic student.
\end{abstract}

Keywords: kintamani orange, factor analyze, consumer decision, strategy proposed

*Korespondensi Penulis:

Email : srimulyani@unud.ac.id 


\section{PENDAHULUAN}

Jeruk (Citrus sp.) merupakan komoditas buah yang memiliki potensi pasar yang cukup besar dan mempunyai nilai ekonomi tinggi. Banyak manfaat yang dimiliki oleh buah jeruk, diantaranya kandungan vitamin $\mathrm{C}$ yang tinggi, kulitnya dapat menghasilkan minyak yang dapat diolah menjadi mewangian, beberapa jenis jeruk dapat digunakan sebagai obat tradisional. Provinsi Bali merupakan salah satu wilayah penghasil jeruk. Jeruk yang berasal dari Provinsi Bali adalah jenis jeruk Siam, dikenal dengan nama jeruk Kintamani (Citrus Nobilis Lour). Beberapa karakteristik jeruk Kintamani yaitu berwarna hijau kekuningan, bagian dalam jeruk berkerut dan tekstur pori-pori, dan memiliki rasa manis keasaman (Prihatman, 2000).

Konsumen memiliki selera tersendiri terhadap jenis jeruk yang dipilih untuk dikonsumsi. Selera konsumen pada umumnya berubah dari waktu ke waktu. Apabila selera konsumen terhadap suatu barang dan jasa tinggi, maka akan diikuti dengan peningkatan keputusan konsumen dalam pembelian barang dan jasa. Selera konsumen diikuti oleh hal yang ada pada jeruk yang ditawarkan, seperti rasa, ukuran, aroma, warna, maupun harga yang ditawarkan kepada pembeli. Menurut Kotler dan Keller (2009), perilaku konsumen adalah proses pengambilan keputusan yang mensyaratkan aktifitas individu untuk mengevaluasi, memperoleh, menggunakan atau mengatur barang atau jasa.

Penjual jeruk harus memiliki strategi di pasaran agar jeruk yang ditawarkan diminati oleh konsumen. Perencanaan strategi pemasaran harus memperhatikan sisi dari konsumen, sebab konsumen memiliki peranan penting sebagai tolak ukur dalam menentukan keberhasilan suatu barang dan jasa (Suprapti, 2010). Salah satu strategi yang tepat agar dapat berhasil dalam pemasaran produk yaitu dengan strategi segmenting, targeting, dan positioning. Produsen dapat mengklasifikasian konsumen sesuai karakteristik (segmenting), membuat target pasar yang akan dituju sebagai fokus utama pemasaran (targeting), dan menciptakan kepercayaan konsumen pada produk yang ditawarkan (positioning). Positioning mengacu pada penempatan merek atau produk di benak pelanggan dengan produk pesaing lainnya yang berkaitan dengan atribut produk dan keuntungan yang ditawarkan produk (Rangkuti, 2004).

Jeruk Kintamani memiliki pesaing dari jenis jeruk lainnya. Hal ini mengakibatkan produsen harus menampilkan keistimewaan dari jeruk Kintamani agar dapat unggul dengan jeruk lainnya dan diminati konsumen. Keistimewaan yang ditampilkan oleh jeruk Kintamani dapat mendorong minat konsumen untuk membeli jeruk Kintamani. Di Kota Denpasar terdapat banyak pasar tradisional, swalayan, pedagang kaki lima, dan toko buah yang menjual beragam buah jeruk dengan jenis yang beragam. Oleh karena itu produsen atau penjual jeruk Kintamani memerlukan strategi agar jeruk Kintamani lebih diminati oleh konsumen dibandingkan jeruk lainnya.

Penelitian Sudarsana menyatakan bahwa dari 27 variabel yang diidentifikasi, 24 variabel yang tergabung dalam 8 faktor mampu menjelaskan faktorfaktor yang dipertimbangkan konsumen dalam keputusannya untuk berbelanja di supermarket. Dalam penelitian Nadya (2018) menyatakan faktor-faktor bauran pemasaran dan pelayanan berpengaruh pada keputusan pembelian konsumen di Starbucks Beachwalk Mall, Badung.

Berdasarkan uraian diatas, maka perlu dilakukan penelitian analisis keputusan pembelian konsumen terhadap pembelian jeruk Kintamani di Kota Denpasar. Tujuan penelitian ini adalah untuk mengetahui faktor utama dan faktor apa saja yang 
mempengaruhi keputusan konsumen dalam membeli jeruk Kintamani.

\section{METODE PENELITIAN}

\section{Tempat dan Waktu Penelitian}

Penelitian ini dilaksanakan di beberapa pasar, swalayan, pedagang kaki lima, dan toko buah di Kota Denpasar dengan menggunakan metode accidental sampling pada bulan November 2018 .

\section{Tahapan Penelitian}

Tahap awal yang dilakukan adalah melakukan survey pendahuluan terhadap penelitian yang akan dilakukan, kemudian merumuskan masalah dan tujuan penelitian dengan studi pustaka. Selanjutnya melakukan identifikasi variabel-variabel penelitian yakni keputusan konsumen dalam membeli jeruk Kintamani. Variabel ditentukan dari penelitian sebelumnya berdasarkan teori bauran pemasaran dan berdasarkan informasi yang diperoleh dari konsumen di pasar (Tjiptono, 2008). Variabel-variabel telah ditentukan, lalu dilakukan penyusunan kuisioner untuk dibagikan kepada responden. Sampel pada penelitian ini adalah populasi konsumen akhir jeruk Kintamani di Kota Denpasar. Data yang menyatakan jumlah populasi konsumen akhir jeruk Kintamani di Kota Denpasar sampai tahun 2018 belum ada. Sugiyono (2010) menyatakan bahwa bila dalam penelitian akan melakukan analisis faktor, maka jumlah anggota sampel minimal 10 kali dari jumlah variabel yang diteliti. Variabel dalam penelitian ini berjumlah 24, sehingga responden yang dipilih yakni 240 orang yang disebar ke beberapa pasar, swalayan, pedagang kaki lima, dan toko buah di Kota Denpasar.

Tahap awal yang dilakukan yaitu uji validitas dan realibilitas terhadap kusioner yang disusun. Pengujian kuisioner ini dilakukan untuk mengetahui sejauh mana suatu alat ukur dapat dipercaya dan sejauh mana alat ukur dapat mengukur yang ingin diukur. Selanjutnya dilakukan penyebaran kuisioner kepada konsumen jeruk Kintamani di Kota Denpasar. Tahap selanjutnya yaitu pengumpulan data di lokasi penelitian dan dianalisis menggunakan program Microsoft Excel dan SPSS. Tahap selanjutnya yaitu analisis data, didapatkan variabel prioritas serta faktor-faktor yang mempengaruhi keputusan konsumen dalam membeli jeruk Kintamani. Tahapan penelitian dapat dilihat pada Gambar 1.

\section{HASIL DAN PEMBAHASAN}

\section{Uji Validitas dan Reliabilitas}

Uji validitas pada penelitian ini dilakukan dengan memberikan kuisioner kepada 30 orang responden yang merupakan konsumen akhir dari jeruk Kintamani di Kecamatan Kuta Selatan. Data yang diperoleh diolah dengan menggunakan SPSS versi 25.0. Variabel dapat dikatakan valid apabila hasil korelasi positif dan lebih besar dari 0,3 (Sugiyono, 2008). Berdasarkan hasil uji validitas yang dilakukan, didapatkan hasil diatas nilai 0,3 , sehingga semua variabel yang digunakan dinyatakan valid.

Nilai uji reliabilitas dapat dilihat ditunjukkan oleh Cronbach's Alpha dengan bantuan program SPSS versi 25.0 dan dinyatakan reliabel apabila diperoleh nilai 0,6 (Malholtra, 1999). Hasil uji reliabilitas pada penelitian ini menunjukkan nilai Cronbach's Alpha sebesar 0,982. Hasil ini menunjukkan bahwa instrumen penelitian reliabel karena nilai yang dihasilkan lebih besar dari 0,6.

\section{Analisis Faktor}

Berdasarkan penelitian terdahulu dan informasi yang diperoleh dari produsen ditentukan 24 variabel yang diamati berdasarkan faktor-faktor dari keputusan pembelian dalam membeli jeruk Kintamani yang meliputi: kualitas produk, manfaat, pemakai, pesaing, kategori produk, dan harga, berdasarkan beberapa penelitian 
terdahulu, dan berdasakan informasi yang diperoleh dari konsumen, sehingga dapat diketahui variabel-variabel yang dipertimbangkan konsumen dalam mengambil keputusan untuk membeli jeruk Kintamani di Kota Denpasar. Data yang diperoleh diolah dengan metode analisis faktor menggunakan program SPSS versi
25.0 dan menghasilkan matrik korelasi. Matriks korelasi dapat mengetahui variabelvariabel yang saling berhubungan dengan ketentuan nilai determinasi yang mendekati nilai nol, dengan nilai KMO (Kaiser Mayer Olkin) lebih besar dari 0,5. Uji Bartlett dengan signifikan mendekati nol dan uji MSA harus menunjukkan di atas 0,5.

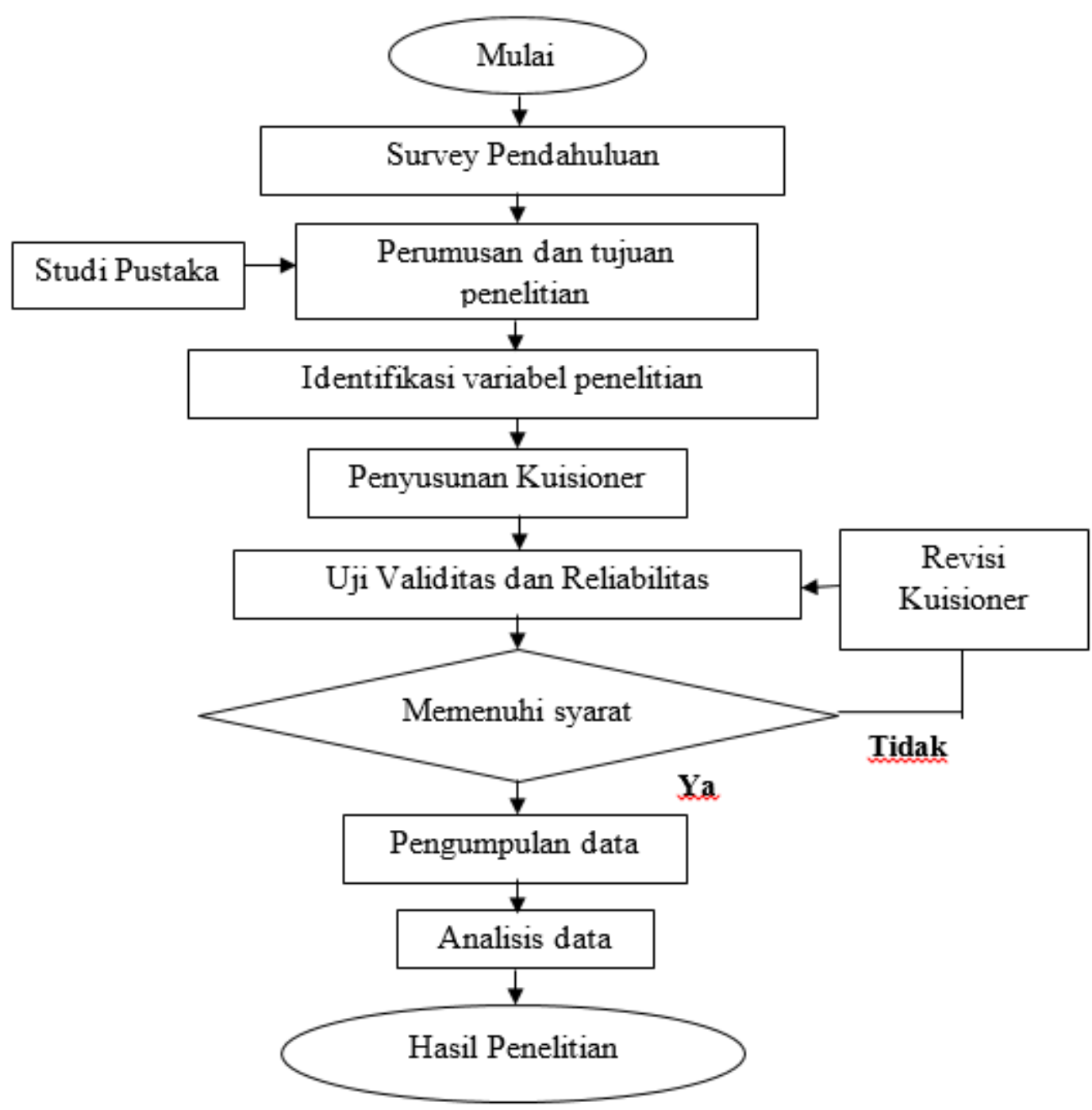

Gambar 1. Tahapan Penelitian

\section{Nilai Determinasi Matriks Korelasi}

Jika angka dari nilai matriks korelasi semakin dekat dengan nol, maka hal ini menunjukkan bahwa antar variabel terbukti saling berkaitan (Malholtra, 1999). Nilai determinasi matriks korelasi yang diperoleh menunjukkan angka yang mendekati nol, yaitu 0,284. Hal ini menunjukkan bahwa antar variabel terbukti berhubungan.

Uji KMO (Kaiser Mayer Olkin)

Nilai uji KMO harus lebih besar dari 
0,5 untuk membuktikkan sampel telah cukup difaktorkan (Malholtra, 1999). Nilai yang diperoleh dari hasil analisis uji KMO adalah 0,896 . Hal ini menunjukkan bahwa jumlah sampel sudah baik dan mencukupi.

\section{Uji Bartlet}

Model faktor dapat digunakan jika nilai signifikan yang diperoleh pada uji Bartlett adalah < 0,05 (Malholtra,1999). Hasil uji Barteltt pada hasil analisis diperoleh nilai sebesar 5059,650 dengan signifikasi 0,000. Hasil ini menunjukkan bahwa antar variabel terjadi korelasi dan peluang kesalahan antar variabel tidak saling independen $(0 \%)$ sehingga model faktor dapat digunakan.

\section{Uji MSA}

Variabel-variabel dapat digunakan kedalam model dan dilakukan analisis lebih lanjut apabila nilai yang diperoleh dari hasil uji MSA $\geq 0,5$ (Santoso, 2006). Hasil uji MSA menunjukkan hasil yakni dari 24 variabel yang diamati ternyata tidak terdapat variabel yang harus dikeluarkan dari model karena telah memenuhi kriteria MSA. Hal ini diketahui dari nilai empat besaran yaitu nilai determinan matriks korelasi, uji $\mathrm{KMO}$, uji Bartlett, dan uji MSA yang telah memenuhi persyaratan analisis faktor.

\section{Penentuan Jumlah Faktor}

Ekstraksi faktor adalah tahapan selanjutnya untuk menentukan jumlah faktor yang terbentuk didasarkan pada total eigenvalues, percentage of variance, dan cumulative percentage. Suatu faktor dapat menjadi pertimbangan keputusan pembelian konsumen berdasarkan eigenvalue yang menunjukkan nilai diatas $>1,0$ (Malholtra, 1999), jika didasarkan pada percentage of variance dengan nilai $>0,5 \%$. Apabila terdapat faktor yang memiliki percentage of variance diatas $5 \%$, maka faktor tersebut dapat digunakan pada model. Jika didasarkan pada cumulative percentage nilai minimum yang dipenuhi adalah $60 \%$. Terdapat 5 faktor yang dipertimbangkan konsumen dalam keputusannya membeli jeruk Kintamani di Kota Denpasar. Kelima faktor tersebut dapat menjelaskan semua varian yang ada dalam data sebesar $80,761 \%$, seperti terlihat dalam tabel 1 berikut ini :

Tabel 1. Hasil ekstraksi faktor

\begin{tabular}{cccc}
\hline Faktor & Eigenvalue & \% of Variance & Cumulative \\
\hline 1 & 6,845 & 28,521 & 28,521 \\
2 & 4,921 & 20,506 & 49,027 \\
3 & 3,790 & 15,793 & 64,820 \\
4 & 2,531 & 10,547 & 75,367 \\
5 & 1,284 & 5,349 & 80,716 \\
\hline
\end{tabular}

\section{Rotasi Faktor}

Faktor matriks menunjukkan faktor yang tidak sederhana strukturnya dan sulit diinterpretasikan, sehingga dilakukan rotasi faktor. Rotasi faktor dilakukan untuk memperoleh struktur yang sederhana sehingga mudah untuk menjelaskan semua faktor yang dianalisis dalam model. Rotasi faktor yang digunakan pada penelitian ini adalah rotasi varimax.

Berdasarkan Tabel 2 pada rotated component matrix, terlihat jelas keanggotaan dari masing-masing faktor. Variabel X1, X3, $\mathrm{X} 5, \mathrm{X} 6, \mathrm{X} 15, \mathrm{X} 16, \mathrm{X} 17, \mathrm{X} 23$ yang mengelompok pada faktor 1 yang menunjukkan item-item pertanyaan (variabel) tersebut merupakan komponen dari faktor 1. Variabel X7, X8, X10, X11, X21, $\mathrm{X} 24$ yang mengelompok pada faktor 2 yang menunjukkan item-item pertanyaan (variabel) tersebut merupakan komponen dari faktor 2. Variabel X2, X4, X9, X18, X20 
yang mengelompok pada faktor 3 yang menunjukkan item-item pertanyaan (variabel) tersebut merupakan komponen dari faktor 3. Variabel X12, X13, X14 yang mengelompok pada faktor 4 yang menunjukkan item-item pertanyaan (variabel) tersebut merupakan komponen dari faktor 4. Variabel X19, X22 yang mengelompok pada faktor 5 yang menunjukkan item-item pertanyaan (variabel) tersebut merupakan komponen dari faktor 5 .

Tabel 2. Rotasi komponen matriks

\begin{tabular}{|c|c|c|c|c|c|}
\hline & \multicolumn{5}{|c|}{ Component } \\
\hline & 1 & 2 & 3 & 4 & 5 \\
\hline $\mathrm{X} .1$ & .884 &,- 028 &,- 059 &,- 062 &,- 087 \\
\hline$\times .2$ &,- 066 &,- 062 & .880 &,- 001 &,- 028 \\
\hline$\times .3$ & .919 &,- 123 &,- 069 &,- 059 &,- 025 \\
\hline$\times .4$ &,- 064 &,- 068 & 879 &,- 039 &, 002 \\
\hline$\times .5$ & .877 &,- 042 & -.073 &,- 071 & .012 \\
\hline$\times .6$ & .874 &,- 086 &,- 082 &,- 053 &,- 083 \\
\hline$\times .7$ &,- 043 & .832 & .002 &,- 046 &, 014 \\
\hline$\times .8$ & -.084 & 897 & -.050 &,- 030 &,- 055 \\
\hline$\times .9$ & -095 & -046 & 918 &,- 056 &,- 013 \\
\hline$\times .10$ & -.042 & .886 & -.049 & -.081 & -.036 \\
\hline$\times .11$ &,- 107 & 848 &,- 048 &,- 044 &,- 039 \\
\hline$\times .12$ &,- 095 &,- 131 &,- 074 & ,898 &,- 037 \\
\hline$\times .13$ &,- 103 &,- 024 &,- 023 & .895 &,- 086 \\
\hline$\times .14$ &,- 125 &,- 096 &,- 097 & .895 &,- 115 \\
\hline$\times .15$ & .887 &,- 015 &,- 138 &,- 036 &,- 001 \\
\hline$\times .16$ & .882 &,- 089 &,- 046 &,- 023 &,- 063 \\
\hline$\times .17$ & 875 &,- 084 &,- 105 &,- 122 &,- 070 \\
\hline$\times .18$ & -.086 &,- 007 & .865 &,- 028 & -.087 \\
\hline$\times .19$ &,- 170 &,- 063 &,- 094 &,- 100 &, 912 \\
\hline$\times .20$ &,- 118 &,- 085 & .882 &,- 089 &,- 087 \\
\hline$\times 21$ & -.055 & .903 & -.071 &,- 042 &,- 039 \\
\hline$\times .22$ &,- 031 &,- 115 &,- 092 &,- 130 &, 918 \\
\hline$\times .23$ & .869 & -.027 & .019 &,- 034 & .030 \\
\hline$\times .24$ & -.077 & ,901 & -.071 &,- 045 &,- 063 \\
\hline
\end{tabular}

\section{Interpretasi Faktor}

Interpretasi faktor dilakukan dengan cara mengelompokkan variabel-variabel yang memiliki faktor loading yang tinggi kedalam faktor tersebut. Faktor loading mengidentifikasi korelasi antar variabel dengan faktor yang bersangkutan. Semakin tinggi faktor loading maka semakin erat hubungan antar variabel tersebut. Penentuan tingkat minimum faktor loading dalam analisis faktor bersifat relatif dan tidak ada ketentuan baku. Hasil interpretasi penelitian ini yaitu faktor loading yang kurang dari 0,4 dikeluarkan dari model. Pada tabel dibawah ini dapat dilihat ke 24 variabel yang tersebar kedalam lima faktor yang merupakan variabel-variabel yang dipertimbangkan konsumen dalam membeli jeruk Kintamani di Kota Denpasar. Lima faktor yang terdiri dari 24 variabel dibentuk menjadi lima faktor dengan nama faktor yang baru yaitu faktor 1 (Karakteristik jeruk sesuai dengan harga dan pesaing), faktor 2 (Manfaat dan mutu jeruk sesuai dengan harga dan golongan produk), faktor 3 (Asal jeruk sesuai dengan manfaat dan persepsi konsumen), faktor 4 (Golongan konsumen jeruk), dan faktor 5 (Ketahanan jeruk). Hasil interpretasi faktor dapat dilihat pada tabel 4.

\section{Faktor 1 (Karakteristik jeruk sesuai dengan harga dan pesaing)}

Rasa jeruk Kintamani yang memiliki perpaduan manis dan asam, memiliki rasa jeruk yang lebih baik dari jeruk lainnya, jeruk Kintamani memiliki perpaduan warna kuning dan hijau, memiliki warna yang lebih menarik dari jeruk lainnya, aroma jeruk Kintamani yang menarik dan lebih menarik dari jeruk lainnya, mempunyai kandungan vitamin $\mathrm{C}$ dan memiliki yang baik untuk mencegah sariawan, dan harganya yang sangat terjangkau merupakan faktor yang dipertimbangkan konsumen dalam keputusannya membeli jeruk Kintamani di Kota Denpasar (Eigenvalue sebesar 6,845). Mayoritas konsumen jeruk Kintamani di Kota Denpasar adalah masyarakat beragama Hindu, sehingga jeruk Kintamani dipakai untuk sarana upacara. Warna yang menarik membuat tampilan jeruk sangat bagus dilihat ketika dipakai untuk sarana upacara selain rasanya yang manis dan asam, aroma yang menarik dan kandungan vitamin $\mathrm{C}$ pada jeruk Kintamani. Jeruk Kintamani juga merupakan 
jeruk yang tidak mahal sehingga masyarakat Kota Denpasar memutuskan untuk membeli jeruk Kintamani. Menurut penelitian Akbarsyah (2013), variabel produk, pesaing, harga, dan manfaat mempunyai pengaruh yang positif terhadap keputusan konsumen dalam melakukan pembelian produk. Variabel produk merupakan variabel yang paling berpengaruh dalam pengambilan keputusan pembelian yang meliputi rasa, aroma, warna, dan harga.

\section{Faktor 2 (Manfaat dan mutu jeruk sesuai dengan harga dan golongan produk)}

Harga jeruk Kintamani sesuai dengan yang ditawarkan, jeruk Kintamani dipakai untuk sarana upacara, jeruk Kintamani dapat dijadikan minuman, jeruk Kintamani termasuk dalam jeruk dengan harga yang tidak mahal, jeruk Kintamani dapat dijadikan olahan makanan, jeruk Kintamani dapat menjadi makanan penutup merupakan faktor yang dipertimbangkan konsumen dalam keputusannya membeli jeruk Kintamani di Kota Denpasar (Eigenvalue sebesar 4,921). Masyarakat Kota Denpasar banyak menggunakan jeruk Kintamani sebagai sarana upacara. Selain sarana upacara, jeruk Kintamani juga digunakan dalam bentuk olahan lain seperti olahan makanan dan minuman. Di beberapa restoran atau rumah makan, jeruk Kintamani digunakan sebagai makanan penutup. Dengan harga yang terjangkau, masyarakat Kota Denpasar cenderung untuk membeli jeruk Kintamani dibanding jeruk lainnya jika dilihat dari mutu dan manfaatnya. Menurut penelitian Marhamah (2016), variabel manfaat merupakan variabel yang berpengaruh terhadap niat perilaku konsumen pada belanja online di Jawa Barat. Dengan adanya belanja online, maka konsumen dapat dengan mudah berbelanja tanpa bepergian keluar rumah. Pada jeruk Kintamani, manfaatnya sangat bagus untuk kesehatan, dapat diolah dalam bentuk makanan, minuman, maupun makanan penutup.

Faktor 3 (Asal, manfaat, dan karakter fisik jeruk sesuai dengan persepsi konsumen)

Kulit jeruk Kintamani dapat dijadikan buah tangan, jenis jeruk Kintamani adalah jeruk yang muncul dalam ingatan saya jika mengatakan kata jeruk, jeruk Kintamani berasal dari daerah Kintamani, Bali, jeruk Kintamani memiliki kulit yang tebal, ukuran jeruk Kintamani lebih besar dari jeruk lainnya merupakan faktor yang dipertimbangkan konsumen dalam keputusannya membeli jeruk Kintamani di Kota Denpasar (Eigenvalue sebesar 3,790). Variabelvariabel yang tercakup ke dalam faktor-faktor mampu menjelaskan keragaman variabel sebesar $15,793 \%$ jika dilihat dari faktor loading. Jeruk yang paling diingat ketika ditanya tentang jeruk adalah jeruk Kintamani karena jeruk ini sangat digemari masyarakat Kota Denpasar. Ukuran jeruk Kintamani tidak terlalu kecil dan tidak terlalu besar, memiliki kulit yang tebal dan berserabut banyak dan dapat dijadikan buah tangan. Hal ini yang menjadikan jeruk Kintamani diminati konsumen di Kota Denpasar. Menurut penelitian Rangkuti (2004), variabel manfaat, kategori produk, produk, dan pesaing merupakan variabel yang berpengaruh terhadap keputusan konsumen untuk membeli produk. Persepsi adalah sekumpulan ingatan akan penilaian yang terbentuk dan melekat dibenak konsumen. Masyarakat Kota Denpasar sudah sangat kenal dengan jeruk Kintamani karena berasal dari Provinsi Bali.

\section{Faktor 4 (Golongan konsumen jeruk)}

Jeruk Kintamani dapat dikonsumsi oleh semua usia, konsumen jeruk Kintamani adalah semua golongan masyarakat, konsumen jeruk Kintamani adalah semua tingkatan masyarakat yang memiliki penghasilan merupakan faktor yang dipertimbangkan konsumen dalam keputusannya membeli jeruk Kintamani di 
Kota Denpasar (Eigenvalue sebesar 2,531).

Tabel 4. Hasil Interpretasi Faktor

\begin{tabular}{|c|c|c|c|}
\hline Faktor & Variabel (X) & $\begin{array}{l}\text { Faktor } \\
\text { Loading }\end{array}$ & $\begin{array}{l}\text { Eigen } \\
\text { Value }\end{array}$ \\
\hline 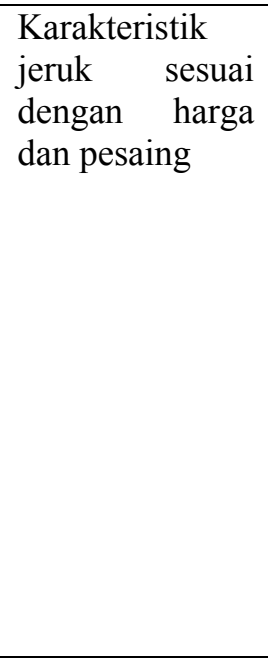 & $\begin{array}{l}\text { Rasa jeruk Kintamani adalah perpaduan manis dan } \\
\text { asam (X3) } \\
\text { Rasa jeruk Kintamani lebih baik dari jeruk lainnya } \\
\text { (X15) } \\
\text { Jeruk Kintamani memiliki perpaduan warna kuning } \\
\text { dan hijau (X1) } \\
\text { Warna jeruk Kintamani lebih menarik dibanding jeruk } \\
\text { lainnya (X16) } \\
\text { Jeruk Kintamani mempunyai aroma yang menarik } \\
\text { (X5) } \\
\text { Aroma jeruk Kintamani lebih disukai dibanding jeruk } \\
\text { lainnya (X17) } \\
\text { Jeruk Kintamani memiliki kandungan vitamin C yang } \\
\text { baik untuk mencegah sariawan (X6) } \\
\text { Harga jeruk Kintamani sangat terjangkau (X23) }\end{array}$ & $\begin{array}{l}0,919 \\
0,887 \\
0,884 \\
0,882 \\
0,877 \\
0,875\end{array}$ & 6,845 \\
\hline $\begin{array}{lr}\text { Faktor } 2 & \\
\text { Manfaat dan } \\
\text { mutu jeruk } \\
\text { sesuai dengan } \\
\text { harga } \\
\text { golongan } \\
\text { produk }\end{array}$ & $\begin{array}{l}\text { Harga jeruk Kintamani sesuai dengan kualitas jeruk } \\
\text { (X24) } \\
\text { Jeruk Kintamani dipakai untuk sarana upacara (X8) } \\
\text { Jeruk Kintamani dapat dijadikan minuman (X10) } \\
\text { Jeruk Kintamani termasuk dalam jeruk dengan harga } \\
\text { yang tidak mahal (X21) } \\
\text { Jeruk Kintamani dapat dijadikan olahan makanan } \\
\text { (X11) } \\
\text { Jeruk Kintamani dapat menjadi makanan penutup (X7) }\end{array}$ & $\begin{array}{l}0,901 \\
0,897 \\
0,886 \\
0,882 \\
0,848 \\
0,832\end{array}$ & 4,921 \\
\hline $\begin{array}{l}\text { Faktor } 3 \\
\text { Asal, manfaat, } \\
\text { dan karakter } \\
\text { fisik jeruk } \\
\text { sesuai dengan } \\
\text { persepsi } \\
\text { konsumen }\end{array}$ & $\begin{array}{l}\text { Kulit jeruk Kintamani dapat dijadikan buah tangan } \\
\text { (X9) } \\
\text { Jenis jeruk Kintamani adalah jeruk yang muncul dalam } \\
\text { ingatan saya jika mengatakan kata jeruk (X20) } \\
\text { Jeruk Kintamani berasal dari daerah Kintamani, Bali } \\
\text { (X2) } \\
\text { Jeruk Kintamani memiliki kulit yang tebal (X4) } \\
\text { Ukuran jeruk Kintamani lebih besar dari jeruk lainnya } \\
\text { (X18) }\end{array}$ & $\begin{array}{l}0,918 \\
0,882 \\
0,880 \\
0,879 \\
0,865\end{array}$ & 3,790 \\
\hline $\begin{array}{l}\text { Faktor } 4 \\
\text { Golongan } \\
\text { konsumen jeruk }\end{array}$ & $\begin{array}{l}\text { Jeruk Kintamani dapat dikonsumsi oleh semua usia } \\
\text { (X12) } \\
\text { Konsumen jeruk Kintamani adalah semua golongan } \\
\text { masyarakat (X13) } \\
\text { Konsumen jeruk Kintamani adalah semua tingkatan } \\
\text { masyarakat yang memiliki penghasilan (X14) }\end{array}$ & $\begin{array}{l}0,898 \\
0,895 \\
0,895\end{array}$ & 2,531 \\
\hline $\begin{array}{l}\text { Faktor } 5 \\
\text { Ketahanan dan } \\
\text { bagian dalam } \\
\text { jeruk }\end{array}$ & $\begin{array}{l}\text { Jeruk Kintamani adalah jeruk yang memiliki ketahanan } \\
\text { lebih baik dari jeruk lainnya (X22) } \\
\text { Bagian dalam jeruk Kintamani memiliki karakteristik } \\
\text { yang berbeda dengan jeruk lainnya (X19) }\end{array}$ & 0,918 & 1,284 \\
\hline
\end{tabular}

Jeruk Kintamani digemari oleh semua usia dan dapat dikonsumsi oleh semua orang.
Jeruk Kintamani memiliki harga yang terjangkau sehingga semua orang dengan 
semua tingkat penghasilan berbeda dapat membeli jeruk Kintamani. Hal tersebut merupakan faktor yang membuat konsumen memutuskan untuk membeli jeruk Kintamani. Menurut penelitian Hasma (2012), variabel pemakai berpengaruh terhadap keputusan konsumen dalam

\section{Faktor 5 (Ketahanan dan bagian dalam jeruk)}

Jeruk Kintamani adalah jeruk yang memiliki ketahanan lebih baik dari jeruk lainnya, bagian dalam jeruk Kintamani memiliki karakteristik yang berbeda dengan jeruk lainnya merupakan faktor yang dipertimbangkan konsumen dalam keputusannya membeli jeruk Kintamani di Kota Denpasar (Eigenvalue sebesar 1,284). Variabel-variabel yang tercakup ke dalam faktor-faktor mampu menjelaskan keragaman variabel sebesar 5,349\% jika dilihat dari faktor loading. Jeruk Kintamani memiliki kulit yang tebal dan memiliki serabut yang banyak di bagian dalam jeruk, sehingga jeruk Kintamani memiliki ketahanan yang baik dalam segala bentuk kerusakan. Hal tersebut merupakan salah satu faktor konsumen untuk memutuskan membeli jeruk Kintamani. Menurut penelitian Zeithamal (1988), penilaian konsumen pada variabel pesaing dan kategori produk akan keunggulan dan keistimewaan secara menyeluruh terhadap suatu produk dapat meningkatkan kualitas produk yang akan meningkatkan keputusan konsumen untuk membeli produk.

\section{Ketepatan Model}

Langkah terakhir pada analisis faktor yaitu penentuan ketepatan model. Model analisis faktor perlu diuji ketepatannya sehingga diketahui apakah model dapat menjelaskan dengan baik. Dasar pengujian ketepatan model adalah dengan melihat persentase jumlah residual yaitu perbedaan korelasi yang diamati dengan korelasi berdasarkan estimasi faktor matriks. Hasil membeli produk. Semakin tinggi produsen meningkatkan strategi positioningnya berdasarkan pemakai produknya, maka semakin tinggi keputusan pembelian konsumen, hal ini dikarenakan buah jeruk mayoritas digemari masyarakat kecuali yang memiliki alergi terhadap buah jeruk.

ketepatan model menunjukkan terdapat 21 (7\%) data nilai residual yang tidak berlebih dengan nilai absolute $>0,05$. Hasil ini menunjukkan bahwa model dapat diterima dengan ketepatan model sebesar $80,71 \%$.

\section{KESIMPULAN DAN SARAN}

\section{Kesimpulan}

Berdasarkan penelitian yang telah dilakukan maka dapat disimpulkan beberapa hal sebagai berikut :

1. Faktor-faktor yang mempengaruhi keputusan konsumen dalam membeli jeruk Kintamani di Kota Denpasar adalah: (1) Karakteristik jeruk sesuai dengan harga dan pesaing, (2) Manfaat dan mutu jeruk sesuai dengan harga dan golongan produk, (3) Asal, manfaat, dan karakter fisik jeruk sesuai dengan persepsi konsumen, (4) Golongan konsumen jeruk, (5) Ketahanan dan bagian dalam jeruk.

2. Faktor yang paling berpengaruh terhadap keputusan pembelian jeruk Kintamani di Kota Denpasar adalah faktor karakteristik jeruk sesuai dengan harga (variabel rasa jeruk Kintamani adalah perpaduan rasa manis dan asam) dengan nilai faktor loading sebesar 0,919.

\section{Saran}

Untuk meningkatkan minat konsumen dalam melakukan pembelian buah jeruk Kintamani maka perlu memperhatikan faktor pesaing (Rasa jeruk Kintamani lebih baik dari jeruk lainnya, warna jeruk Kintamani lebih menarik dibanding jeruk lainnya, aroma jeruk Kintamani lebih disukai dibanding jeruk 
lainnya, ukuran jeruk Kintamani lebih besar dari jeruk lainnya, bagian dalam jeruk Kintamani memiliki karakteristik yang berbeda dengan jeruk lainnya) dari jeruk lainnya, serta mutu dan kualitas jeruk yang dihasilkan.

\section{DAFTAR PUSTAKA}

Akbarsyah, 2013. Analisis Pengaruh Strategi Positioning Terhadap Keputusan Konsumen Dalam Melakukan Pembelian Pada Coffee Toffee Urip Sumoharjo di Makassar. Skripsi. Fakultas Ekonomi dan Bisnis, Universitas Hasanudin, Makassar.

Hasma, L. 2012. Analisis Pengaruh Strategi Positioning Terhadap Keputusan Pembelian Pada Konsumen Starbucks Coffee Di Makassar. Skripsi. Fakultas Ekonomi dan Bisnis, Universitas Hasanudin, Makassar.

Kotler, P., dan K. L. Keller. 2009. Manajemen Pemasaran : Definisi Konsumen. Pretince Hall. New Jersey.

Malholtra, N. K. 1999. Marketing Research. Prentice Hall, Inc., New Jersey.

Marhamah, S. 2016. Pengaruh Faktor-Faktor Pembentuh Perilaku Konsumen Terhadap Niat Perilaku Konsumen Pada Belanja Online (Studi Kasus pada Pengguna Smartphone di Jawa Barat). Jurnal Manajemen Ekonomi, 3 (2) : 18.

Nadya, K., A. S. Wiranatha dan A. Hartiati. 2018. Analisis Bauran Pemasaran dan Pelayanan yang Mempengaruhi Keputusan Pembelian Konsumen di
Starbucks Beachwalk Mall, Badung. Jurnal Rekayasa dan Manajemen Agroindustri, 6 (1) : 22-32.

Prihatman, K. 2000. Jeruk (Citrus sp). Deputi Menegristek Bidang Pendayagunaan dan Pemasyarakatan Ilmu Pengetahuan dan Teknologi. Jakarta.

Priyatno, D. 2010. Teknik Mudah dan Cepat Melakukan Analisis Data Penelitian dengan SPSS dan Tanya Jawab Ujian Pendadaran. Gava Media.Yogyakarta.

Rangkuti, F. 2004. Manajemen Persediaan Aplikasi di Bidang Bisnis. PT. Raja Grafindo Persada. Jakarta.

Santoso, 2006. SPSS Statistika Multivariat. PT. Elex Media Komputindo. Jakarta.

Sudarsana, I. N. 2007. Faktor-Faktor yang dipertimbangkan Konsumen dalam Keputusannya Berbelanja pada Supermarket Delta Dewata Ubud Gianyar. Skripsi. Fakultas Ekonomi. Universitas Udayana.

Sugiyono, M. 2008. Metode Penelitian Pendidikan. Alfabeta. Bandung.

Suprapti, L. 2010. Analisis Pengaruh Brand Awareness, Perceived Value, Organizational Association dan Perceived Quality Terhadap Keputusan Pembelian Konsumen. Jurnal Riset Pemasaran. 3 (5) : 24-25.

Tjiptono, F, 2008, Strategi Pemasaran, Edisi Ketiga. ANDI. Yogyakarta.

Zeithamal, V. 1988, "Consumer Perceptions of Price, Quality, and Value: a meansend model and synthesis of the evidence". Journal of Marketing. 52 (3) : $2-22$ 